\title{
Aerothermodynamic Testing of the Crew Exploration Vehicle in the LaRC 20-Inch Mach 6 and 31-Inch Mach 10 Tunnels
}

\author{
Karen T. Berger* \\ Langley Research Center, Hampton, VA, 23681-2199
}

\begin{abstract}
An experimental wind tunnel program is being conducted in support of a NASA wide effort to develop a Space Shuttle replacement and to support the Agency's long term objective of returning to the Moon and Mars. This report documents experimental measurements made on several scaled ceramic heat transfer models of the proposed Crew Exploration Vehicle Crew Module. The experimental data highlighted in this test report are to be used to assess numerical tools that will be used to generate the flight aerothermodynamic database. Global heat transfer images and heat transfer distributions were obtained over a range of freestream Reynolds numbers and angles of attack with the phosphor thermography technique. Heat transfer data were measured on the forebody and afterbody and were used to infer the heating on the vehicle as well as the boundary layer state on the forebody surface. Several model support configurations were assessed to minimize potential support interference. In addition, the ability of the global phosphor thermography method to provide quantitative heating measurements in the low temperature environment of the capsule base region was assessed. While naturally fully developed turbulent levels were not obtained on the forebody, the use of boundary layer trips generated fully developed turbulent flow. Laminar and turbulent computational results were shown to be in good agreement with the data. Backshell testing demonstrated the ability to obtain data in the low temperature region as well as demonstrating the lack of significant model support hardware influence on heating.
\end{abstract}

\begin{tabular}{|c|c|c|c|}
\hline \multirow{3}{*}{$\begin{array}{l}\text { D } \\
h\end{array}$} & \multicolumn{3}{|c|}{ Nomenclature } \\
\hline & diameter & $\mathrm{T}$ & temperature $\left({ }^{\circ} \mathrm{F}\right)$ \\
\hline & Heat transfer coefficient & $\mathrm{x}$ & axial distance from origin (in) \\
\hline & $(-\dot{q}$ & & \\
\hline & $H-H_{w}$ & $\begin{array}{l}\text { Greek } \\
\alpha\end{array}$ & angle of attack (deg) \\
\hline$h_{\text {ref }}$ & reference heat-transfer coefficient using & $\delta$ & boundary-layer height (in) \\
\hline & Fay-Riddell calculation & $\theta$ & boundary-layer momentum thickness (in) \\
\hline $\mathrm{H}$ & Stagnation enthalpy $\left(\mathrm{BTU} / \mathrm{lb}_{\mathrm{m}}\right)$ & & \\
\hline $\mathrm{k}$ & boundary-layer trip height (in) & Subscri & \\
\hline $\mathrm{L}_{\text {ref }}$ & reference length (in) & 1 & free-stream conditions \\
\hline M & Mach number & aw & adiabatic wall \\
\hline$P$ & pressure, psia & $\mathrm{t}, 1$ & reservoir condition \\
\hline q & dynamic pressure (psi) & t,2 & stagnation conditions behind normal shoc \\
\hline$\dot{q}$ & heat transfer rate $\left(\mathrm{BTU} / \mathrm{ft}^{2}-\mathrm{sec}\right)$ & $\mathrm{w}$ & wall \\
\hline $\mathrm{r}$ & radius (in) & $\infty$ & free-stream conditions \\
\hline $\operatorname{Re}$ & unit Reynolds number (1/ft) & & \\
\hline & time $(\mathrm{sec})$ & & \\
\hline
\end{tabular}

\section{Introduction}

Officially designated as "Orion", the Crew Exploration Vehicle (CEV) Crew Module was initially designed as a blunt body capsule with a diameter of $18.04 \mathrm{ft}$. This geometry was referred to as Cycle I. Iterations on the geometry

${ }^{*}$ Aerospace Engineer, Aerothermodynamics Branch, MS 408A, Member 
resulted in Cycle II, with a diameter of $16.5 \mathrm{ft}$, truncation of the backshell length and a reduction of the aft backshell radius. The Cycle I geometry was used for this testing and is shown in Fig. 1.

The Crew Exploration Vehicle (CEV) will ultimately be capable of transporting four crew members for lunar missions and later supporting crew transfers for Mars missions. In the near term, the CEV will be capable of transporting up to six crew members to and from the International Space Station. Despite the geometric simplicity of the basic Apollo-like capsule concept, many differences between CEV and Apollo remain. The CEV must be cost effective and certain elements of the spacecraft must be reusable. To accommodate a larger crew complement, the Crew Module will be larger; with a heat shield diameter approximately 30\% larger than Apollo (16.5 ft vs. $12.8 \mathrm{ft}$ ). To maintain a land based recovery option while meeting disposal requirements of the service module prior to entry, the hypersonic trim angle-of-attack of the CEV was initially targeted at $152 \mathrm{deg}$. The current heat shield design uses a Phenolic Impregnated Carbon Ablator (PICA) to protect the spacecraft during re-entry into earth's atmosphere as compared to Apollo's glass-phenolic ablative honeycomb heatshield. Similar to Apollo, pyrolysis/outgassing of the heat shield as it ablates during entry will occur. Boundary layer transition to turbulent flow is likely to be induced earlier in the trajectory as compared to a non-ablative heat shield and significant material recession is anticipated. The thermal protection system (TPS) community has taken a conservative approach and is currently designing the heat shield for fully turbulent flow from entry interface along the entire trajectory. Recent work indicates that the initial Cycle I geometry and trim angle of attack may not be applicable, but because these initial experimental studies were designed for computational fluid dynamics (CFD) code validation, the data collected on the Cycle I geometry at $152 \mathrm{deg}$ are still valuable (the OML and flight angle of attack are shown in Fig. 1b).

The primary objective of the test entry into the Langley Research Center (LaRC) 20-Inch Mach 6 Air Tunnel was to measure benchmark turbulent heating on the CEV heat shield. To support CFD turbulence modeling best practices and to assess numerical uncertainties, natural transition to turbulent flow was desired over turbulent flow induced from surface roughness. Test parametrics in Mach 6 included freestream unit Reynolds numbers of $2.1 \times 10^{6} / \mathrm{ft}-7.3 \times 10^{6} / \mathrm{ft}$ at a fixed angle-of-attack of $152 \mathrm{deg}$ as well as a range of model diameters to increase length Reynolds numbers and improve the likelihood of achieving fully developed natural turbulent flow on the heat shield. A boundary layer trip strategy was developed in the event that fully developed turbulent heating could not be achieved naturally. Limited measurements on the CEV backshell were made to assess potential model support system interference on surface heating and to determine the response of the phosphor measurement technique in regions of low surface temperature.

The primary objective of the test entries into the LaRC 31-Inch Mach 10 Tunnel was to characterize the phosphor temperature response in a facility with a higher temperature driver potential (and potentially higher signalto-noise ratio and correspondingly lower measurement uncertainties than the Mach 6 facility). Measurements similar to those obtained in the Mach 6 tunnel were obtained to assess support system interference as well as the viability of testing the backshell surfaces in either facility. Heating levels in the higher temperature facility were desired for code validation on the backshell. Test parametrics in the Mach 10 facility included freestream unit Reynolds numbers of $1.0 \times 10^{6} / \mathrm{ft}-1.9 \times 10^{6} / \mathrm{ft}$ at a fixed angle-of-attack of $152 \mathrm{deg}$

\section{Experimental Methods}

These experiments were completed in the NASA Langley Research Center's 20-Inch Mach 6 and 31-Inch Mach 10 Air Tunnels. Descriptions of the models, wind tunnels and the Global Phosphor Thermography System are presented.

\section{A. Model/Support Hardware}

Two model scales were tested in this study. The initial Outer Mold Line (OML) of the CEV Crew Module was a blunt body capsule with a diameter of $18.04 \mathrm{ft}$. This OML was referred to as Cycle I. This diameter makes the 5 and 7 -in. diameter tunnel models $2.2 \%$ and $3.2 \%$ scale respectively. A reference model OML is shown in Fig 1. At the time of initial model design, it was determined that all initial aerothermal CEV testing would utilize the Cycle I geometry. Prior to primary contractor down select, an iteration on this OML was made. Cycle II is a geometric scaling of Cycle I from a diameter of $18.04 \mathrm{ft}$ to $16.5 \mathrm{ft}$, a truncation of the backshell length and a reduction on the radius on the aft backshell.

The 5 and 7-in. cast ceramic models used in the Mach 6 and 10 test series were manufactured from molds created from rapid prototyped resin patterns. Standard methods, materials and equipment developed at LaRC were used in fabricating the ceramic aeroheating test models ${ }^{1}$. Due to the symmetry of the CEV capsule models, casting molds were created directly from the resin patterns bypassing the wax pattern requirement. This step is note worthy as in general it has been determined that shrinkage in the wax patterns introduce the largest uncertainty in the final ceramic OML. Specific model dimensions are shown in Table 1. All models were supported by a cylindrical sting 
and one of two base mounting techniques: (1) a straight sting mounted through the axis of symmetry and (2) a sting aligned $28 \mathrm{deg}$ from the axis of symmetry in order to place the sting in the shadow of the flow (both shown in Fig 1). Fiducial marks were applied to the model surface using a coordinate measuring machine. The reference marks on the model surface were used to align the model in the tunnel and to aid heat data reduction.

The 5-in. models were mounted with both of the support hardware configurations. This procedure allowed for testing and imaging of the windward afterbody largely mitigating the influence of the support hardware. All 7-in. diameter models were mounted with the straight sting only. All 5-in. models were mounted with 0.75 -in. diameter stainless steel stings, and the 7-in. models were mounted with 1.0-in. diameter stainless steel stings.

(a)

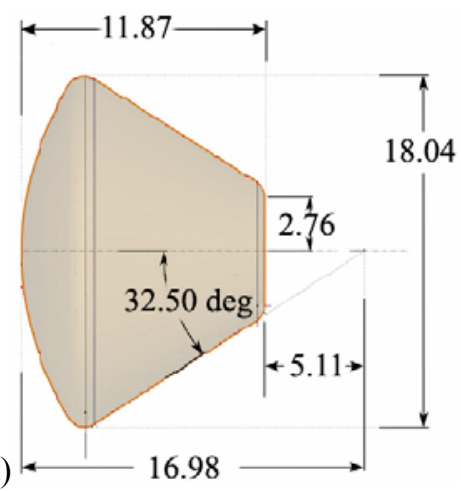

(b)

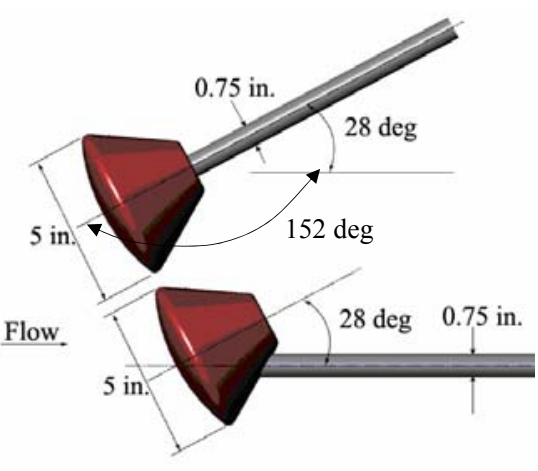

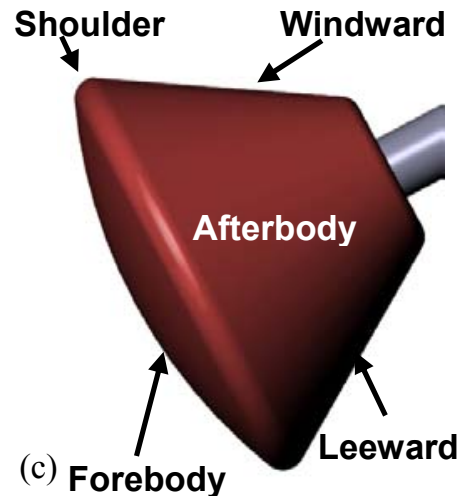

Figure 1: CEV Cycle I OML and Dimensions: (a) full scale (ft), (b) tunnel scale (in), (c) model surface terminology

Table 1: CEV Model Nominal and Measured Dimensions

\begin{tabular}{|c|c|c|c|c|c|c|c|}
\hline & $\begin{array}{c}\text { Nose } \\
\text { Cone } \\
\text { Radius } \\
\text { (in) }\end{array}$ & $\begin{array}{c}\text { Cone } \\
\text { Diameter } \\
\text { (in) }\end{array}$ & $\begin{array}{c}\text { Cone } \\
\text { Base } \\
\text { Diameter } \\
\quad \text { (in) }\end{array}$ & $\begin{array}{c}\text { Total } \\
\text { Cone } \\
\text { Length } \\
\text { (in) }\end{array}$ & $\begin{array}{l}\text { Cone } \\
\text { Angle } \\
\text { (deg) }\end{array}$ & $\begin{array}{c}\text { Front } \\
\text { Shoulder } \\
\text { Radius } \\
\text { (in) }\end{array}$ & $\begin{array}{c}\text { Base } \\
\text { Shoulder } \\
\text { Radius } \\
\text { (in) }\end{array}$ \\
\hline $\begin{array}{c}\text { Cycle I } \\
\text { 5" Model Nominal }\end{array}$ & 6.000 & 5.000 & 1.780 & 3.290 & 32.500 & 0.250 & 0.250 \\
\hline $5 "$ Straight Sting & 5.989 & 4.962 & 1.788 & 3.271 & 32.387 & 0.239 & 0.229 \\
\hline $5 " 28$-deg Sting & 5.990 & 4.969 & 1.785 & 3.290 & 32.326 & 0.241 & 0.220 \\
\hline $\begin{array}{c}\text { Cycle I } \\
\text { 7" Model Nominal }\end{array}$ & 8.400 & 7.000 & 2.493 & 4.603 & 32.500 & 0.350 & $\mathbf{0 . 3 5 0}$ \\
\hline 7" Straight Sting & 8.390 & 6.948 & 2.491 & 4.593 & 32.373 & 0.318 & 0.368 \\
\hline
\end{tabular}

\section{B. Facility}

The data included in this report were obtained in the NASA Langley Aerothermodynamics Laboratory (LAL). Both the 20-Inch Mach 6 Air Tunnel and 31-Inch Mach 10 Air Tunnel have well characterized perfect gas flows in terms of composition and uniformity. Nominal test conditions for the two facilities are shown in Table 2. Flow conditions were acquired using a 16-bit analog-to-digital facility acquisition system. The values of $\mathrm{P}_{t, 1}$ and $\mathrm{T}_{\mathrm{t}, 1}$ are believed to be accurate to within $\pm 2 \%$. The uncertainties in the angle of attack of the model are believed to be $\pm 0.2^{\circ}$.

20-Inch Mach 6 Tunnel: The Langley 20-Inch Mach 6 Air Tunnel $^{2}$ is a blow down wind tunnel that uses dry air as the test gas. Air from two high pressure bottle fields is transferred to a 600-psia reservoir and is heated to a maximum temperature of $1000^{\circ} \mathrm{R}$ by an electrical resistance heater. A double filtering system is employed having an upstream filter capable of capturing particles larger than 20 microns and a second filter rated at 5 microns. The filters are installed between the heater and settling chamber. The settling chamber contains a perforated conical baffle at the entrance and internal screens; the maximum operating pressure is 525 psia. A fixed geometry, two-dimensional contoured nozzle is used; the top and bottom walls of the nozzle are contoured and the sides are parallel. The nozzle throat is $0.34 \mathrm{in}$. by $20 \mathrm{in}$., the test section is $20.5 \mathrm{in.}$ by $20 \mathrm{in}$., and the nozzle length from the throat to the test section window center is $7.45 \mathrm{ft}$. This tunnel is equipped with an adjustable second minimum and exhausts either into combined $41-\mathrm{ft}$ diameter and $60-\mathrm{ft}$ diameter vacuum spheres, a $100-\mathrm{ft}$ diameter vacuum sphere, or to the atmosphere 
through an annular steam ejector. The maximum run time is 20 minutes with the ejector, though heating tests generally have total run times of $30 \mathrm{sec}$, with actual model residence time on tunnel centerline of approximately 5-10 sec. Models are mounted on the injection system located in housing below the closed test section. This system includes a computer operated sting support system capable of moving the model through an angle of attack range of -5 to +55 deg and angles of sideslip of $\pm 8 \mathrm{deg}$.

31-Inch Mach 10 Tunnel: The Langley 31-Inch Mach 10 Air Tunnel $^{2}$ is a blow down wind tunnel that uses dry air as the test gas. The facility consists of a high pressure air storage system having a volume of $865 \mathrm{ft}^{3}$ and rated at 4400 psia maximum, a 12.5-MW electrical resistance heater located in a vertical pressure vessel, a 5-micron in-line filter, settling chamber, three dimensional contoured nozzle, 31-in. square closed test section, adjustable second minimum, after cooler, steam ejector, vacuum spheres and vacuum pumps. The settling chamber, nozzle throat section, test section, adjustable second minimum, and subsonic diffuser are all water cooled. The 12-in. diameter settling chamber is equipped with screens at the upstream end and is faired into the upstream end of a square cross section nozzle having a 1.07 -in. square throat. The throat section is one piece fabricated from beryllium copper, and backside water-cooled with the cooling water system operating at 500 psia. Models are supported on a hydraulicallyoperated, sidewall-mounted injection system. The angle of attack can be varied from -90 to +90 deg and the tunnel has a 14-in. inviscid core. Sideslip range is $\pm 5 \mathrm{deg}$. With the second minimum closed to about 25 percent of the maximum test section cross section area and the use of two 41-ft diameter vacuum spheres, run times up to 2 min. can be achieved, though heating tests generally have total run times of $30 \mathrm{sec}$, with actual model residence time on tunnel centerline of approximately 5-10 sec.

Table 2: Nominal Test Conditions for 20-In Mach 6 and 31-In Mach 10 Air Tunnels

\begin{tabular}{|c|c|c|c|c|c|c|c|c|c|c|c|c|}
\hline Tunnel & $\begin{array}{c}\text { Test } \\
\text { Gas }\end{array}$ & $\begin{array}{c}\mathrm{P}_{\mathrm{t}, 1,} \\
\mathrm{psi}\end{array}$ & $\begin{array}{c}\mathrm{T}_{\mathrm{t}, 1,} \\
{ }_{\mathrm{R}}\end{array}$ & $\begin{array}{c}\mathrm{P}_{\infty}, \\
\mathrm{Psi}_{10} 0^{2}\end{array}$ & $\begin{array}{c}T_{\infty}, \\
{ }^{\circ} \mathrm{R}\end{array}$ & $\begin{array}{c}\mathrm{q}_{\infty}, \\
\mathrm{Psi}\end{array}$ & $\begin{array}{c}\mathrm{V}_{\infty}, \\
\mathrm{ft} / \mathrm{s}\end{array}$ & $\mathrm{M}_{\infty}$ & $\begin{array}{c}\mathrm{R}_{\infty}, \\
\mathrm{ft}^{-1} \mathrm{x}^{-6} 0^{-6}\end{array}$ & $\begin{array}{c}\mathrm{R}_{2}, \\
\mathrm{ft}^{-1} \mathrm{x}^{-5}\end{array}$ & $\mathrm{P}_{2} / \mathrm{P}_{\infty}$ & $\begin{array}{c}\mathrm{P}_{\mathrm{t}, 2,}, \\
\mathrm{psi}\end{array}$ \\
\hline Mach 6 & Air & 29 & 868 & 2.14 & 111.6 & 0.514 & 3020 & 5.86 & 0.533 & 0.934 & 5.25 & 0.956 \\
\hline Mach 6 & Air & 59 & 882 & 4.238 & 111.7 & 1.028 & 3047 & 5.88 & 1.046 & 1.83 & 5.26 & 1.91 \\
\hline Mach 6 & Air & 124 & 922 & 8.12 & 113.7 & 2.03 & 3122 & 5.98 & 1.98 & 3.422 & 5.28 & 3.772 \\
\hline Mach 6 & Air & 250 & 911 & 16.116 & 111.8 & 4.051 & 3103 & 5.99 & 4.043 & 6.933 & 5.28 & 7.528 \\
\hline Mach 6 & Air & 366 & 936 & 23.111 & 114.2 & 5.852 & 3142 & 6.02 & 5.632 & 9.724 & 5.29 & 10.876 \\
\hline Mach 6 & Air & 476 & 930 & 29.813 & 113.1 & 7.573 & 3136 & 6.04 & 7.383 & 12.651 & 5.29 & 14.073 \\
\hline Mach 10 & Air & 348 & 1800 & 0.992 & 95.2 & 0.65 & 4628 & 9.67 & 0.568 & 0.472 & 5.96 & 1.205 \\
\hline Mach 10 & Air & 723 & 1825 & 1.867 & 94.2 & 1.259 & 4670 & 9.81 & 1.104 & 0.898 & 5.98 & 2.334 \\
\hline Mach 10 & Air & 1452 & 1800 & 3.509 & 90.7 & 2.43 & 4643 & 9.94 & 2.24 & 1.755 & 5.98 & 4.503 \\
\hline
\end{tabular}

\section{Experimental Methods}

Global Phosphor Thermography: The two-color relative-intensity phosphor thermography measurement technique $^{3-5}$ was used to obtain global experimental aeroheating data in the tunnel. This technique uses a mixture of phosphors that fluoresce in the bands of the visible spectrum when illuminated with ultraviolet light. The red and green bands are used and the intensity of the fluorescence is dependent upon the amount of incident ultraviolet light and the local surface temperature of the phosphor. This phosphor mixture, which is suspended in a silica ceramic binder and applied with an air brush, is used to coat a slip cast silica ceramic model. The final coating thickness is approximately $0.001 \mathrm{in}$. Using a 3-CCD (Charge Coupled Device) camera, fluorescence intensity images of an illuminated phosphor model exposed to the heated hypersonic flow of the tunnel are acquired and converted to temperature mappings via a temperature-intensity calibration. The temperature-intensity calibration uses the ratio of the red and green components of the image to construct a lookup table which converts the intensities to temperature value. Currently, this calibration is valid over a temperature range from $532{ }^{\circ} \mathrm{R}$ to $800{ }^{\circ} \mathrm{R}$. The temperature data from the time-sequenced images taken during the wind tunnel run are then reduced to an enthalpy based heat transfer coefficient at every pixel on the image (and hence globally on the model) using a heat-transfer calculation assuming one-dimensional semi-infinite slab heat conduction ${ }^{4}$. 
Oil Flow: Oil flow ${ }^{2}$ is a widely used surface flow visualization technique providing streamline pattern information on model surfaces. Models are painted black and then coated with a mixture of oils of various viscosities. A mixture of oil and white pigment is applied and the prepared model is injected into the flow. The movement of the pigmentation the model's surface is primarily recorded by post-run photographs. The movement of oil on the surface of the model is usually insignificant enough during the retraction process enabling the flow patterns to be photographed in great detail over the entire model surface after the removal of the model from the flow. Oil-flow tests were performed to aid in the interpretation of thermal mapping/heat transfer measurements in the Mach 10 facility.

\section{Data Presentation}

Global heating images and the corresponding centerline data cuts will be presented in the $\mathrm{x} / \mathrm{D}$ or $\mathrm{x} / \mathrm{L}$ format for the forebody or afterbody respectively (see Fig 2). All heating data will be provided in the non-dimensionalized $\mathrm{h} / \mathrm{h}_{\text {ref }}$ format and are extracted from a two-dimensional image. The reference $\mathrm{h}$ value is based on the Fay-Riddell hemisphere stagnation point heating equation ${ }^{6}$ with a nose radius of 6.0 and $8.4 \mathrm{in}$. for the 5 and 7-in. diameter models respectively, and a wall temperature of $540^{\circ} \mathrm{R}$.

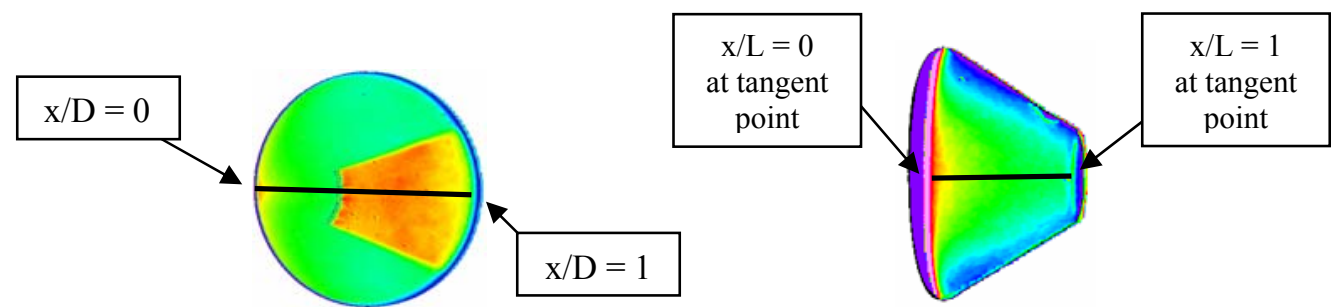

Figure 2: Data Format for Forebody and Afterbody Phosphor Testing

\section{E. Data Quality/Uncertainty}

Uncertainties in the phosphor thermography are based on surface temperature rise, and those presented here are based on historical testing with a variety of model types. On surfaces with significant temperature rise $(60+\operatorname{deg} \mathrm{F})$, such as forebody surfaces, uncertainties are in the range of $\pm 10 \%$. For moderate temperature rise (20-30 deg F) such as the windward afterbody surface, the uncertainties are roughly $\pm 25 \%$. More information on uncertainties in the phosphor thermography can be found in Refs. 4 and 5.

\section{Test Results}

Six separate test entries were completed in two tunnel facilities over a 6 month period. The purpose of these test entries was to assess the viability of aerothermal testing in the facilities and to generate a baseline set of heating data for the forebody and afterbody surfaces. The initial Mach 6 tunnel entry was completed in order to determine the necessity for boundary layer trips, develop a boundary layer tripping strategy and to examine issues of tunnel blockage. A short follow-on test was completed to generate turbulent heating data utilizing lessons learned from the initial entry. In the Mach 10 facility, an initial test entry generated oil flow data, and a series of three short test entries generated heating data. Nominal model installations can be seen in Figs 3-6.

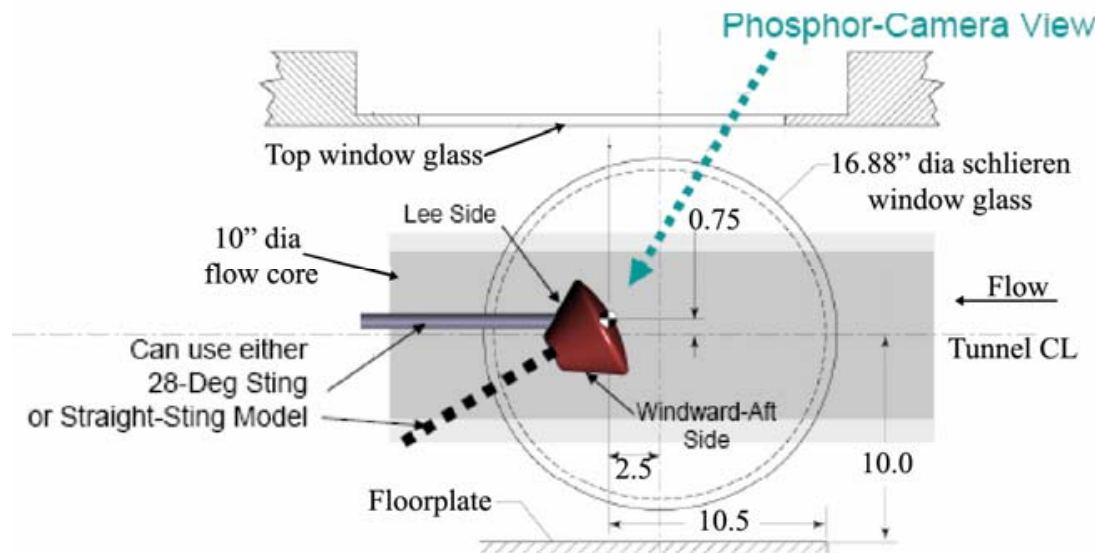

Figure 3: Model Set-Up in the 20-Inch Mach 6 Air Wind Tunnel, NASA LaRC (dimensions in inches) 

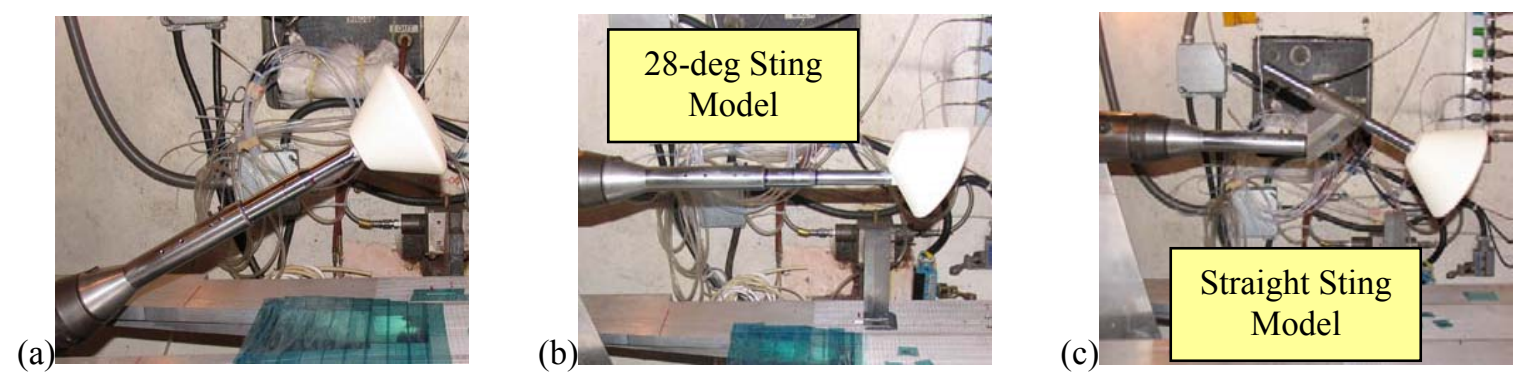

Figure 4: Model Installation at Mach 6 Tunnel; (a) forebody testing with the straight sting model; (b) windward afterbody testing with the 28-deg sting model; (c) windward afterbody testing with the straight sting model

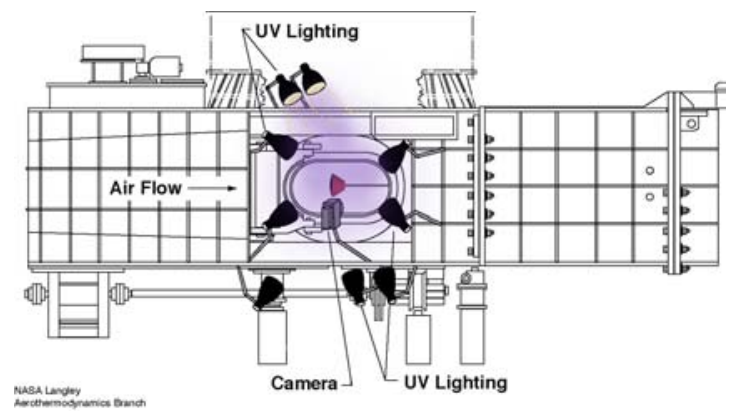

Figure 5: Model Set-Up in the 31-Inch Mach 10 Air Wind Tunnel, NASA LaRC

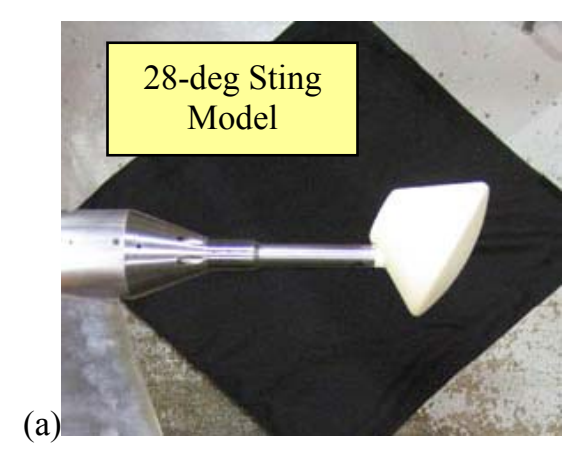

(b)

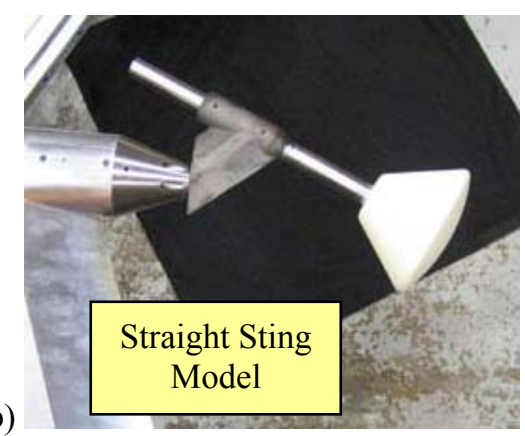

Figure 6: Afterbody Heating Installation at the Mach 10 Tunnel; (a) 28-deg sting model; (b) straight sting model

\section{A. Tunnel Blockage Check}

In general, a larger model size increases the likelihood of achieving naturally turbulent flow in the Mach 6 facility, however, tunnel flow blockage was a concern for testing in both the 20-Inch Mach 6 and 31-Inch Mach 10 facilities. While natural transition to turbulent heating levels is not expected in the Mach 10 tunnel due to the facility's Reynolds numbers range, the characterization of CEV model size limitations in the tunnel was motivated by a future desire to assess micro-aeroheating environments associated with penetrations and/or protuberances in the thermal protection system (TPS). A larger model scale would permit higher fidelity geometry associated with local deviations from the smooth OML in the form of window recessions or antennae fairings. In addition, a larger model would enhance spatial resolution associated with potential interference heating from RCS jet interactions.

5- and 7-in. diameter models were tested in both facilities at the nominal angle of attack, $152 \mathrm{deg}$, as well as at $180 \mathrm{deg}$ angle of attack (heat shield geometric stagnation point at $0 \mathrm{deg}$ ) at low Reynolds number. From a facility performance perspective, a low Reynolds number condition with the model at 180 deg angle-of-attack represents a worst case bounding condition. The test core is the smallest at the lowest Reynolds number, and the projected model frontal area is the largest when the model is at 180 deg angle of attack. If no signs of blockage are present at these conditions, then higher Reynolds number and/or angles of attack do not present tunnel blockage concerns. As shown 
in Table 3 (data are from the initial Mach 6 entry), wall pressure and Mach probe measurements in the Mach 6 Tunnel show no indications of flow blockage due to model size. At all test conditions, the difference between the measured Mach probe data and the tunnel calibration information was less than $0.1 \mathrm{psi}$. A similar study was done in the Mach 10 Tunnel with similar results. Based upon the current assessments performed in the LaRC Mach 6 and 10 Tunnels, it is concluded that a diameter of 7 in. is viable in both facilities.

Table 3: Mach 6 Tunnel Flow Blockage Information

\begin{tabular}{|c|c|c|c|c|c|c|}
\hline $\begin{array}{c}\text { Reynolds } \\
\text { Number }\end{array}$ & Model & $\begin{array}{c}\text { Angle of } \\
\text { Attack }\end{array}$ & $\begin{array}{c}\text { Mach Probe } \\
\text { Measurement }\end{array}$ & $\begin{array}{c}\text { Tunnel } \\
\text { Calibration }\end{array}$ & delta & $\begin{array}{c}\% \\
\text { difference }\end{array}$ \\
\hline$\left(\times 10^{6} / \mathrm{ft}\right)$ & & $(\mathrm{deg})$ & $(\mathrm{psi})$ & $(\mathrm{psi})$ & $(\mathrm{psi})$ & \\
\hline 2.1 & $7^{\prime \prime}$ & 180 & 3.898 & 3.881 & 0.017 & 0.43 \\
\hline 2.1 & No Model & $\mathrm{NA}$ & 3.850 & 3.850 & 0.000 & 0.00 \\
\hline 2.1 & $5^{\prime \prime}$ & 152 & 3.853 & 3.829 & 0.024 & 0.64 \\
\hline 2.1 & $7^{\prime \prime}$ & 152 & 3.834 & 3.836 & 0.002 & 0.06 \\
\hline 4.1 & No Model & $\mathrm{NA}$ & 7.534 & 7.555 & 0.021 & 0.27 \\
\hline 4.1 & $5^{\prime \prime}$ & 152 & 7.593 & 7.567 & 0.027 & 0.35 \\
\hline 4.1 & $7^{\prime \prime}$ & 152 & 7.572 & 7.563 & 0.009 & 0.12 \\
\hline 5.6 & No Model & $\mathrm{NA}$ & 10.844 & 10.933 & 0.089 & 0.82 \\
\hline 5.6 & $5^{\prime \prime}$ & 152 & 10.971 & 10.925 & 0.046 & 0.42 \\
\hline 5.6 & $7^{\prime \prime}$ & 152 & 10.990 & 10.988 & 0.002 & 0.02 \\
\hline 7.3 & No Model & NA & 13.907 & 13.997 & 0.090 & 0.65 \\
\hline 7.3 & $5^{\prime \prime}$ & 152 & 14.088 & 14.099 & 0.010 & 0.07 \\
\hline 7.3 & $7^{\prime \prime}$ & 152 & 13.942 & 13.981 & 0.039 & 0.28 \\
\hline
\end{tabular}

\section{B. Laminar and Turbulent Heating Augmentation Levels}

Only a few runs focusing on forebody heating were completed in the Mach 10 Tunnel. Model support system constraints associated with the side injection system of the Mach 10 Tunnel limit optical access and UV lighting of the CEV (forebody) heat shield. As expected, the model surface temperature on the heat shield exceeded the maximum temperature threshold of the phosphor at the upper Reynolds number range in this facility. At lower Reynolds numbers, regions away from the stagnation region did not saturate and a limited laminar heating distribution was obtained. In regions where the data were obtained, compressibility effects were not evident between Mach 6 and 10, as shown in Fig 7. Based on this study future forebody testing in the Mach 10 Tunnel is not recommended due to over-scaling of the existing thermographic phosphor system over a large portion of the forebody.

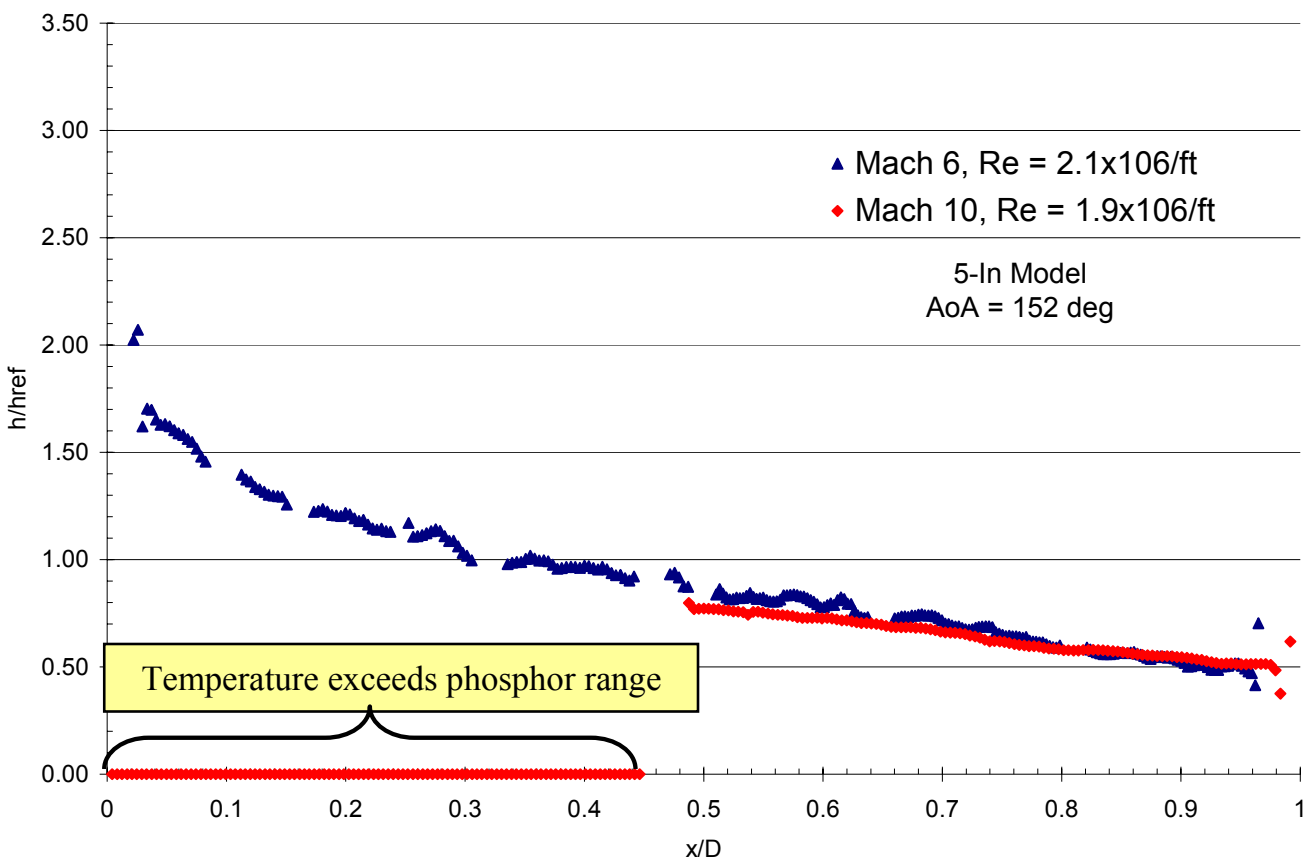

Figure 7: Comparison of Forebody Heating in the Mach 6 and Mach 10 Tunnels 
The primary objective of the Mach 6 test entry was to obtain turbulent data with natural transition if possible and if not through the use of boundary layer trips. For the purposes of the paper, transition onset is defined as the location at which the measured heating distribution departs from a laminar baseline. Data issues associated with phosphor temperature saturation were not evident in the Mach 6 tunnel. As expected, the measured heating distributions at the lower facility Reynolds numbers were essentially invariant with Reynolds number indicative of laminar flow. As evident in Fig 8, transition onset on the CEV heat shield was observed but fully turbulent heating was not achieved (naturally) in the Mach 6 tunnel.

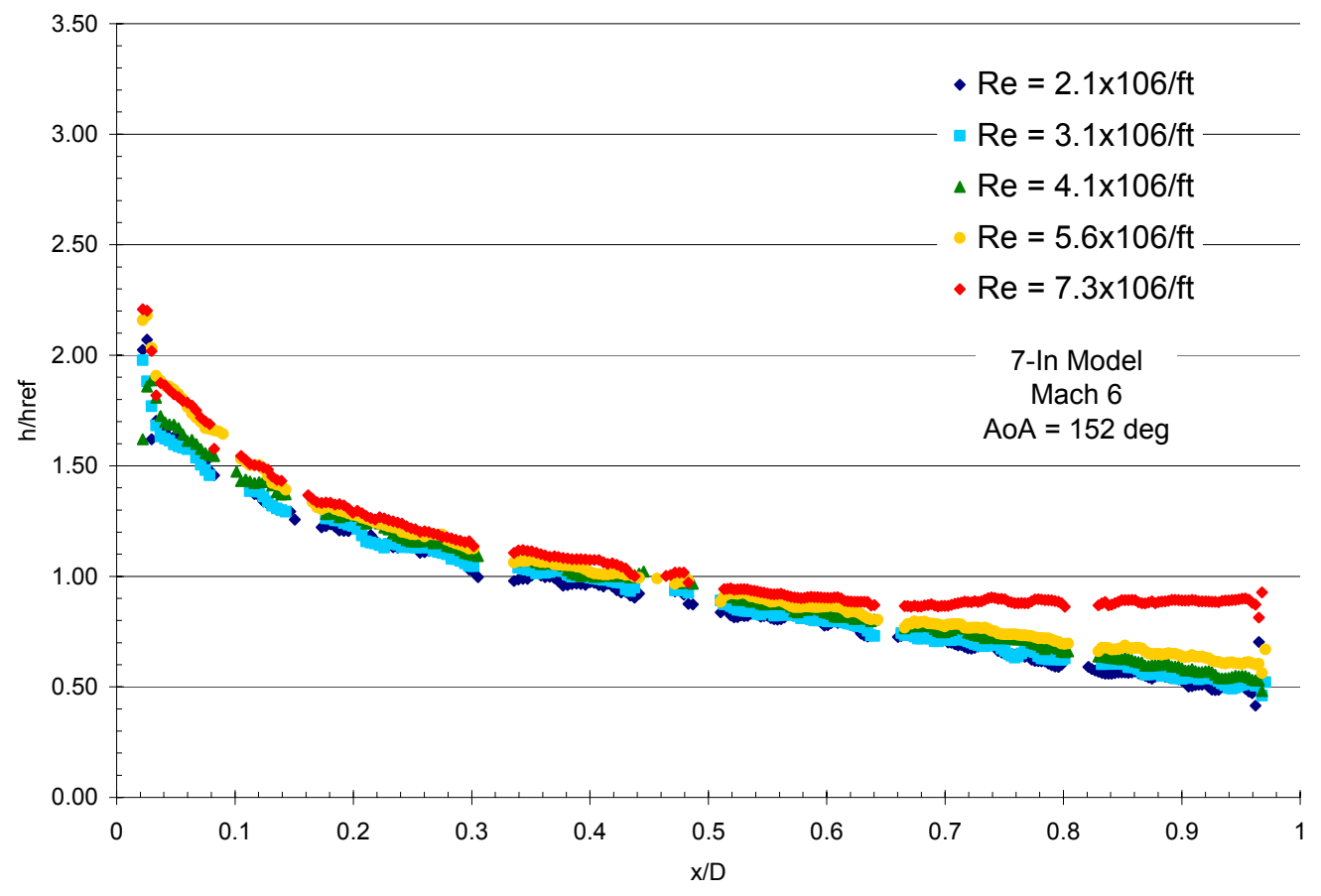

Figure 8: Heating distribution over a range of Reynolds numbers (no trips)

In the event that turbulent heating could not be achieved "naturally," a boundary layer tripping strategy was developed during the initial test entry into the Mach 6 tunnel. The emphasis of the trip screening study was to determine a location and pattern that would ensure uniform turbulent heating over a substantial percentage of the heat shield. The isolated roughness elements used in the CEV trip study have evolved over the last decade ${ }^{7}$. In the manufacturing process, adhesively backed high temperature tape is precut with a laser to the desired square planform shape. Height parametrics are controlled by the tape thickness. As shown in Fig 9, fiducial marks were placed on the model surface to assist in the placement of the boundary layer trips. The $0.05 \times 0.05$-in. protuberances on the model surface are analogous to a "pizza box" on a flat surface. While this paper does not attempt to document the trip screening study, the test results are summarized in Fig 10. It was quickly determined that the local spreading angle of turbulent flow behind a single isolated trip was very small ( $\sim 10 \mathrm{deg})$. The footprint of the flow disturbance created by an individual isolated trip is shown as a region of increased heating. 


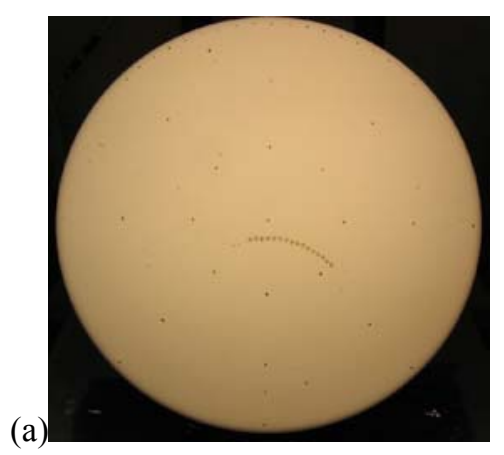

(b)

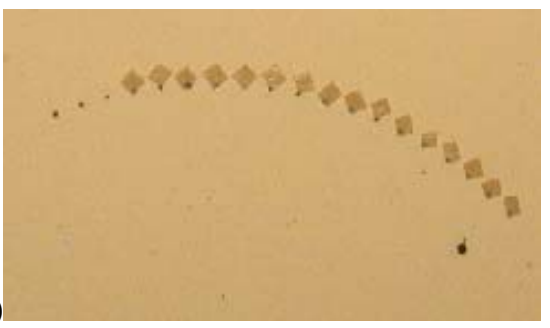

Figure 9: Fiducials and Boundary Layer Trip Placement; (a) boundary later trip array on model; (b) close up view of boundary layer trip array

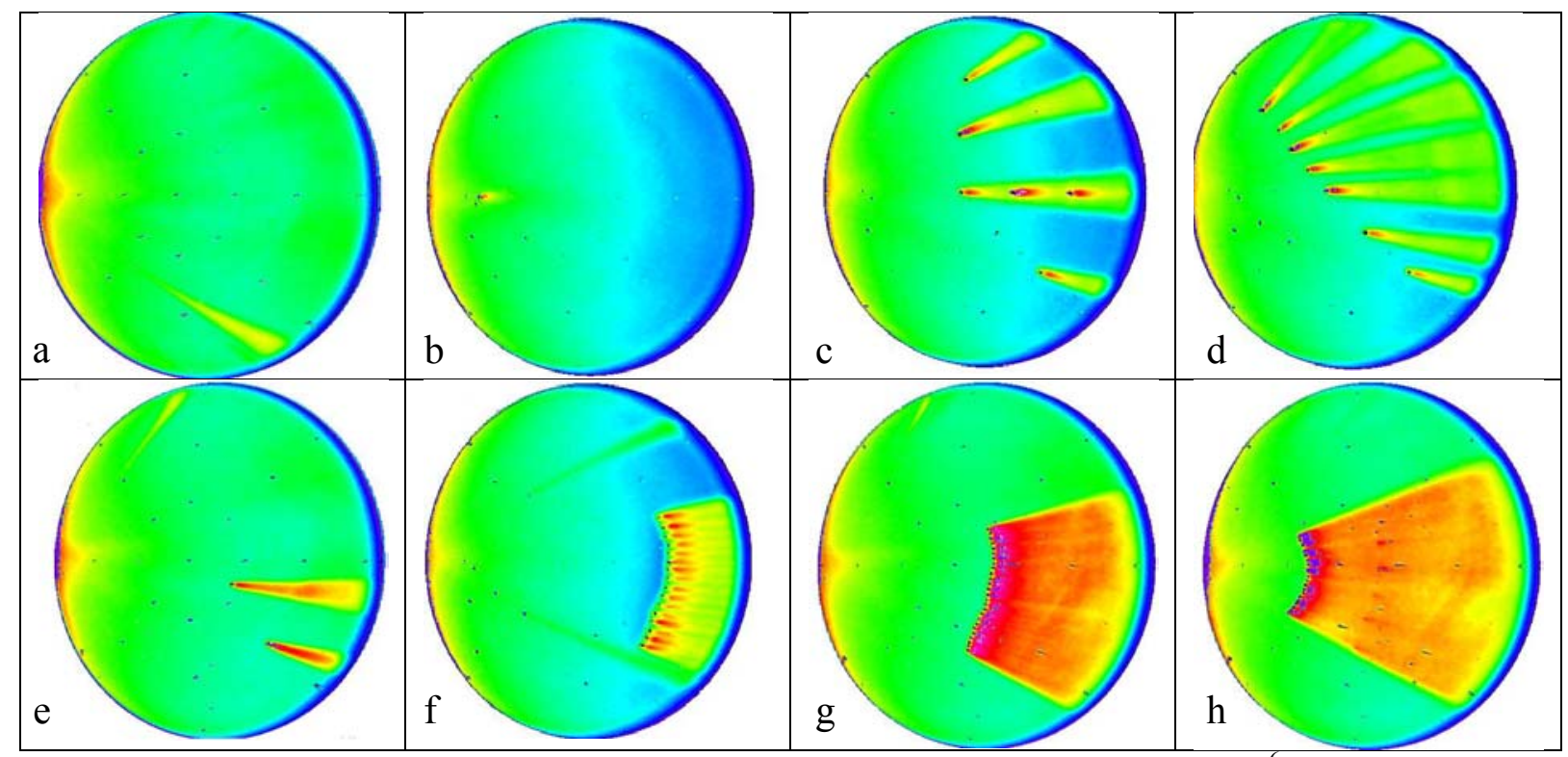

Figure 10: Boundary layer trip locations and orientations at $152 \mathrm{deg} \mathrm{AoA}, \mathrm{Re}=7.3 \times 10^{6} / \mathrm{ft}$. First row, (a) no boundary layer trips, (b) single trip at the stagnation point, (c) 6 boundary layer trips on the centerline and across the model, (d) 7 boundary layer trips in diagonal across the model. Second row, (e) 2 off-center trips at x/D locations of 0.6 and 0.8 , (f) boundary layer trip array at $\mathrm{x} / \mathrm{D}=0.8,(\mathrm{~g})$ boundary layer trip array at $\mathrm{x} / \mathrm{D}=0.6$, (h) boundary layer trip array at $\mathrm{x} / \mathrm{D}=0.4$

It was determined that a single array of trips spaced approximately one trip length apart was most effective at producing a uniform turbulent heating pattern with minimal vortical disturbances. The trip array was placed at an $\mathrm{x} / \mathrm{D}$ location of approximately 0.4 . This location was near the peak $\mathrm{Re}_{\theta} / \mathrm{M}_{\mathrm{e}}$ value on the heat shield as determined by CFD pre-test predictions. ${ }^{8}$ The array crossed the centerline of the model but was not mirrored symmetrically on both sides to allow for a direct comparison of untripped and tripped heating levels off centerline during a single wind tunnel run. Trip heights of $0.0045,0.0065$, and 0.0115 in. were tested and correspond to $\mathrm{k} /$ delta values of approximately $0.4,0.6$, and 1.05 respectively at a unit Reynolds number of $7.3 \times 10^{6} / \mathrm{ft}$.

In Figs 11-13, heating distributions associated with three different boundary layer trips heights are shown for freestream Reynolds numbers of $4.1,5.6$, and $7.3 \times 10^{6} / \mathrm{ft}$ respectively. Fully turbulent flow was not achieved at the lower Reynolds number of $4.1 \times 10^{6} / \mathrm{ft}$ as suggested by the lack of decreasing trend after peak heating (evident in the data at the higher Reynolds numbers and in the predictions), as well as the lack of agreement between measurement and prediction. Large heating peaks in the near wake of the trips were observed at all Reynolds numbers and are presumably associated with the initial vortical flow shed off of the trips. The smallest trips heights appeared to largely eliminate this overshot phenomena. As shown in Figs 12 and 13, within approximately 20 trip lengths, the heating distributions at the two highest Reynolds numbers appeared to asymptotically approach consistent levels regardless of trip height and decrease after peak heating, compelling evidence that the tripped flow has relaxed to 
equilibrium turbulent values at the higher Reynolds numbers. This evidence is further supported by pre-test laminar and turbulent CFD predictions using the Langley Aerothermodynamic Upwind Relaxation Algorithm (LAURA). ${ }^{9,10}$ The predictions using the Cebeci-Smith turbulence model are computed for fully developed turbulent conditions as well as a condition where the CFD prediction used an instantaneous transition from laminar to turbulent at a trip location of $x / D=0.3$. It is of note that both predictions achieve the same heating levels as shown in Figs 12 and 13. The predicted turbulent results are shown to be within $7 \%$ of the experimental measurements at the highest Reynolds number. As a matter of interest, when the two fully turbulent cases, $5.6 \times 10^{6} / \mathrm{ft}$ and $7.3 \times 10^{6} / \mathrm{ft}$, are compared to the laminar cases around $\mathrm{x} / \mathrm{L}=0.8$, the heating augmentation levels are 2.5 and 2.75 respectively.

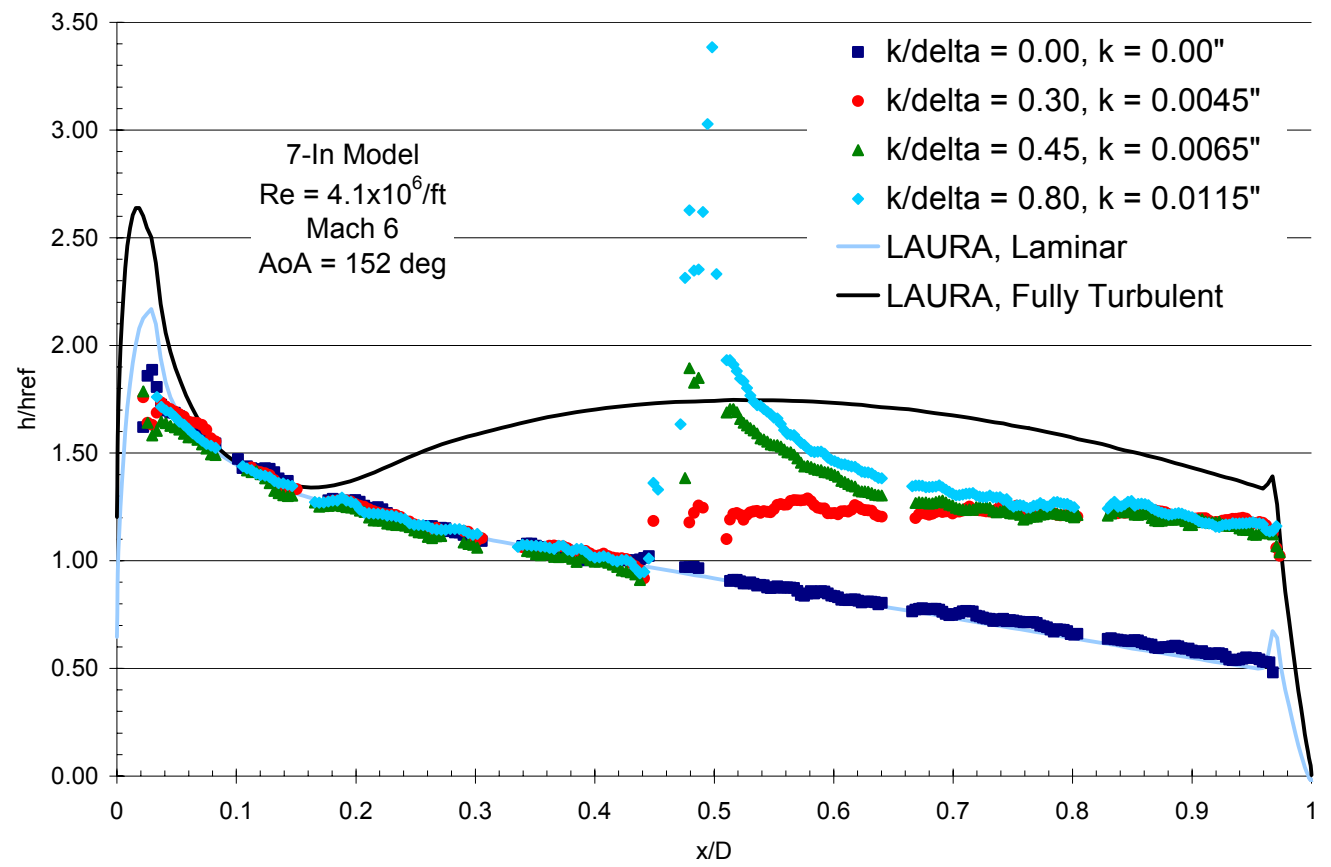

Figure 11: Comparison of symmetry plane experimental and predicted results at $4.1 \times 10^{6} / \mathrm{ft}$

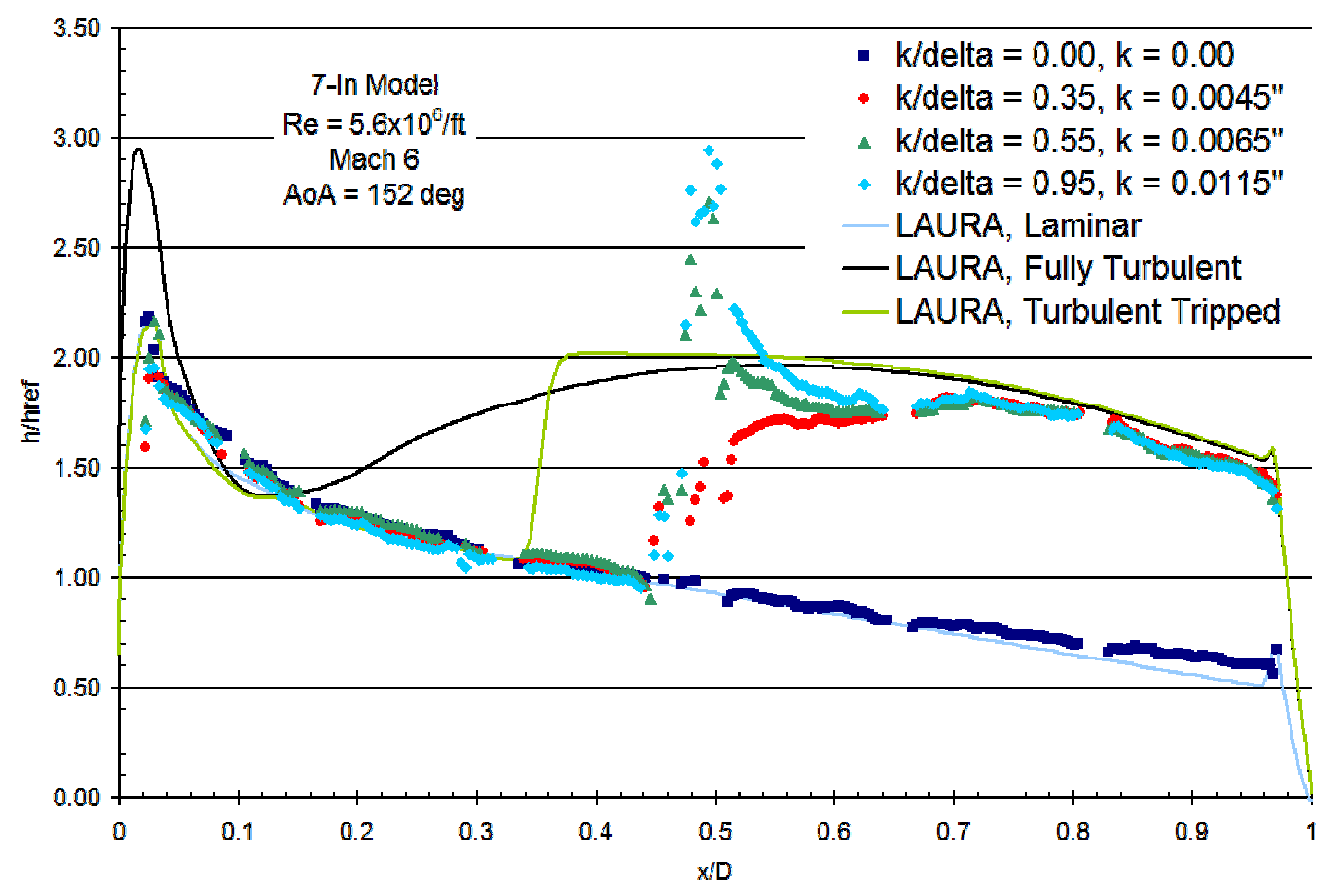

Figure 12: Comparison of symmetry plane experimental and predicted results at $5.6 \times 10^{6} / \mathrm{ft}$ 


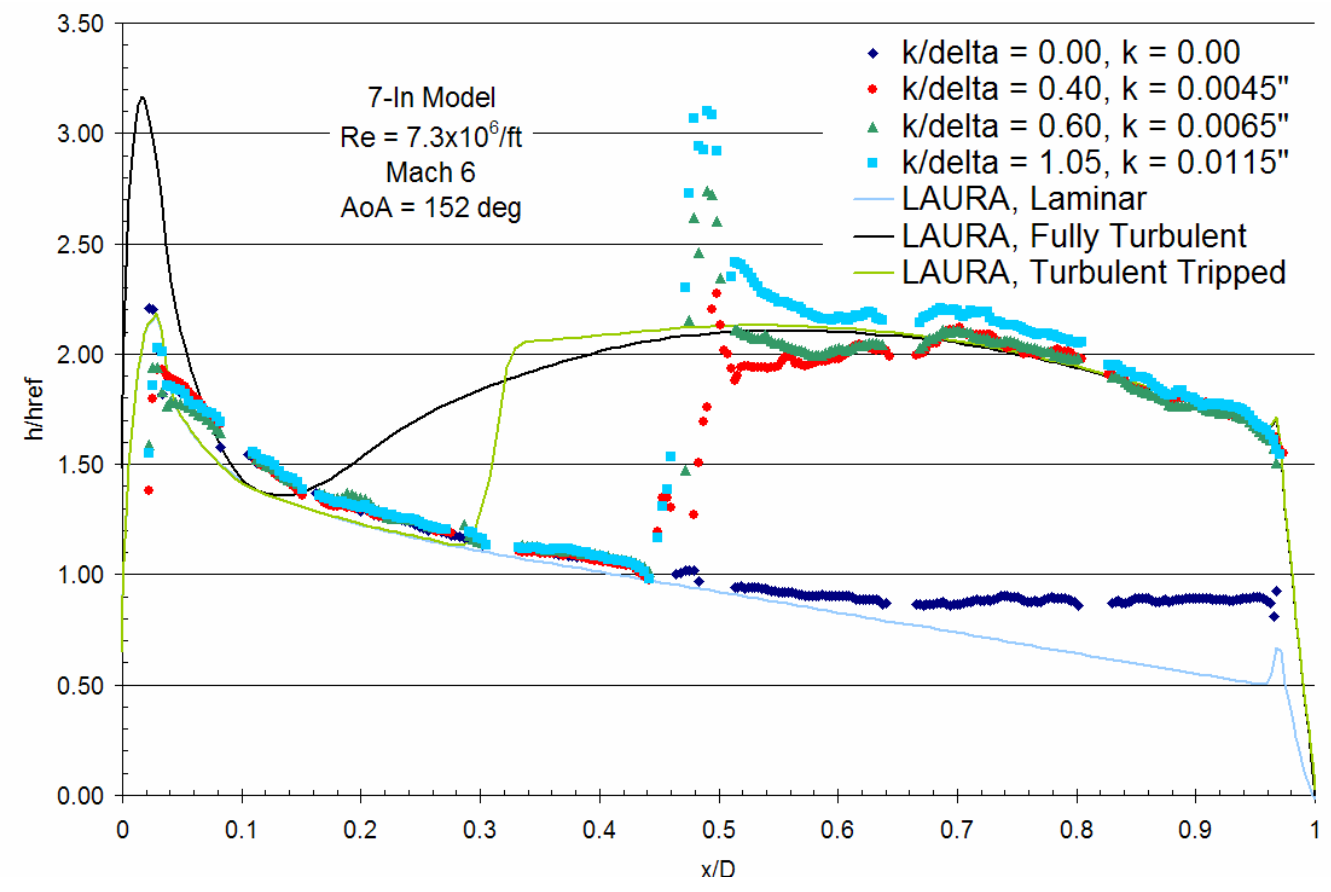

Figure 13: Comparison of symmetry plane experimental and predicted results at $7.3 \times 10^{6} / \mathrm{ft}$

\section{Surface Visualization}

Oil flow surface visualization was used on the two different support hardware configurations tested in the Mach 10 Tunnel. The straight sting model had a cylindrical sting concentric with the $\mathrm{x}$-axis, while the 28-deg sting model had a cylindrical sting offset by $28 \mathrm{deg}$ from this axis and entering the model through the leeward afterbody surface. Blade mounts were not considered in this phase of the testing. Images of both the forebody and afterbody were taken post-run and used to help determine if there were any effects due to the support hardware configuration. Runs were made at Reynolds numbers of $1.0 \times 10^{6} / \mathrm{ft}$ and $1.9 \times 10^{6} / \mathrm{ft}$. Images are shown in Figs 14 and 15 for the $\mathrm{Re}=1.9 \times 10^{6} / \mathrm{ft}$ case. It is important to note that although the same procedure was used for each of the runs, each application of the oil and the paint will have some inherent differences so surface patterns associated with streamlines should be compared. Images were taken post-run and may have some effects of the gravitational pull on the oil and paint.

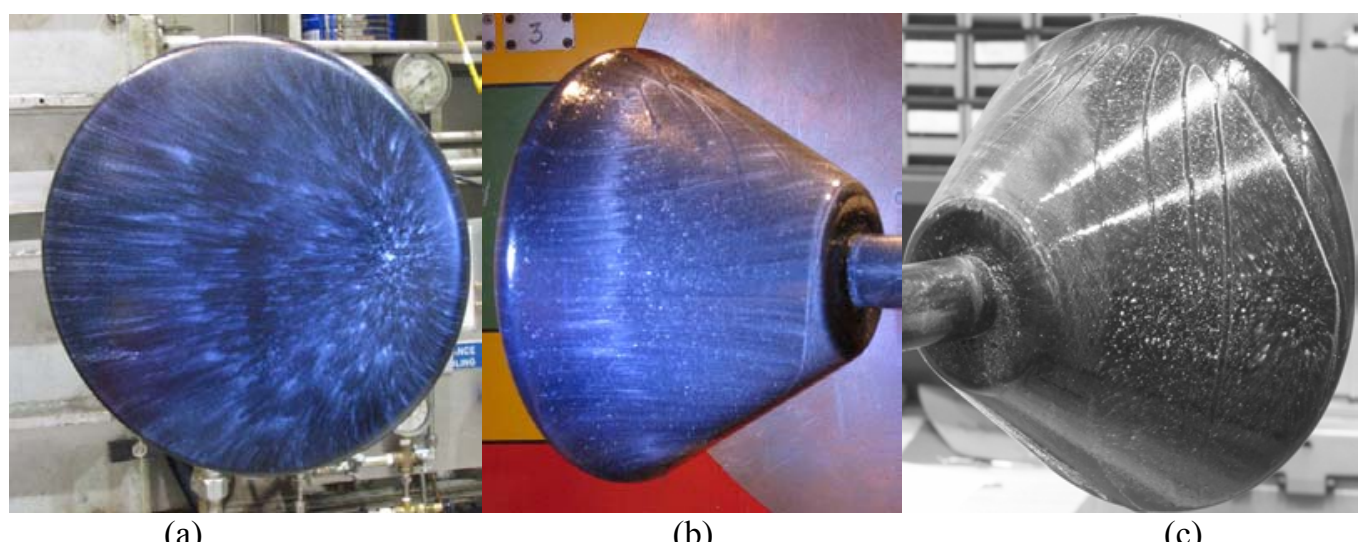

(a)

(b)

(c)

Figure 14: Straight Sting Model: (a) Forebody, (b) Windward Afterbody, (c) Leeside Afterbody 


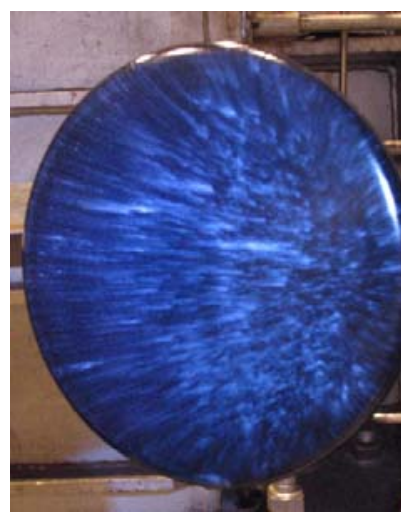

(a)

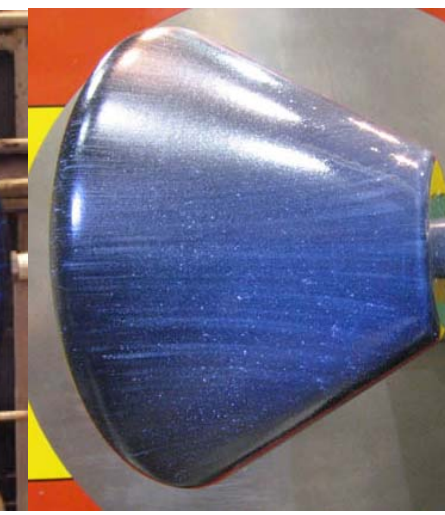

(b)

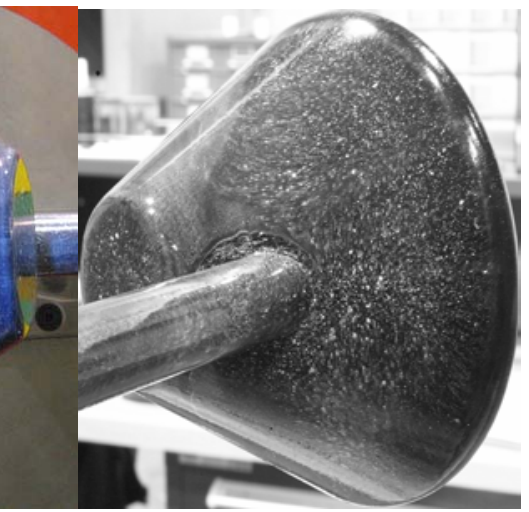

(c)

Figure 15: 28-deg Sting Model: (a) Forebody, (b) Windward Afterbody, (c) Leeside Afterbody

The patterns on the forebody are similar for the two configurations and show that there is no support hardware influence on the forebody surface of the model. On the windward afterbody, the line seen roughly $1 / 3$ of the way from the front shoulder of the straight sting model is a result of oil running from the forebody. The line near the base is a result of the gravitational pull on the oil before the post-run image could be taken. The streamlines from the two different support hardware configurations do not exhibit any significant difference. There are differences to note on the leeside afterbody as a result of the support hardware location. On the straight sting, there is again evidence of the post-run gravitational pull on the oil causing it to run down the model. Some recirculation is shown on the 28-deg sting model immediately forward of the sting. These influences do not seem to feed onto the other surfaces of the model. The same general pattern can be seen on the two models as the windward afterbody is approached from the leeside. These oil flow images show that there is not significant support hardware influence on the forebody or windward afterbody as a result of sting placement. The leeside afterbody is affected, but it is important to note that the measurement of the heating on the leeside of the 28-deg model is not possible due to the sting location.

\section{Windward Afterbody Support Hardware Comparisons}

An objective of the wind tunnel testing was to obtain information on the heating environment on the backshell in order to assess support hardware interference, compare with CFD results and obtain backshell heating levels. Two separate support hardware configurations were tested with the 5 -in. diameter models in order to determine the influences on the afterbody heating associated with the sting placement. On the windward afterbody surface, it was expected that if there was influence, the 28-deg sting would exhibit less influence as it would be completely shadowed within the wake flow when the model was pitched to the trim angle of attack of $152 \mathrm{deg}$.

A range of Reynolds numbers were run in the Mach 6 facility and it was found that there was insufficient temperature rise (less than 5-10 deg) on the afterbody surface at the lower Reynolds numbers $\left(\operatorname{Re}=2.1 \times 10^{6} / \mathrm{ft}\right.$ and $4.1 \times 10^{6} / \mathrm{ft}$ ) to obtain useful data. Figure 16 shows that at the higher Reynolds numbers there was a sufficiently high signal-to-noise ratio to obtain data. The two support hardware configurations exhibited the same heating levels, meaning that there was no influence on the windward afterbody heating levels from the support hardware configuration.

Testing the afterbody in the Mach 10 tunnel was desirable due to the higher tunnel temperature, and thus higher driving potential for implementing the thermographic phosphor system. Both of the sting configurations were tested and just as in the Mach 6 tunnel, there was no significant difference in heating observed based on support hardware configuration. Both the configurations were tested at different Reynolds numbers and did not show an influence due to Reynolds number or support hardware configuration (shown in Fig 17). Similar conclusions can be made based on the computational results. It should be noted that the cause of the disagreement between experimental data and computational predictions near the shoulder of the model has not been identified. It is suspected that it may be the result of fabrication issues associated with the geometry of the corner (shown in Fig. $1 \mathrm{c}$ and associated with $\mathrm{x} / \mathrm{L}=0$ in the data). The computational model incorporates a sharp corner and the experimental model may not be exactly the same in that region. Over the remainder of the afterbody surface, computational predictions seem to match well with the experimental results. 


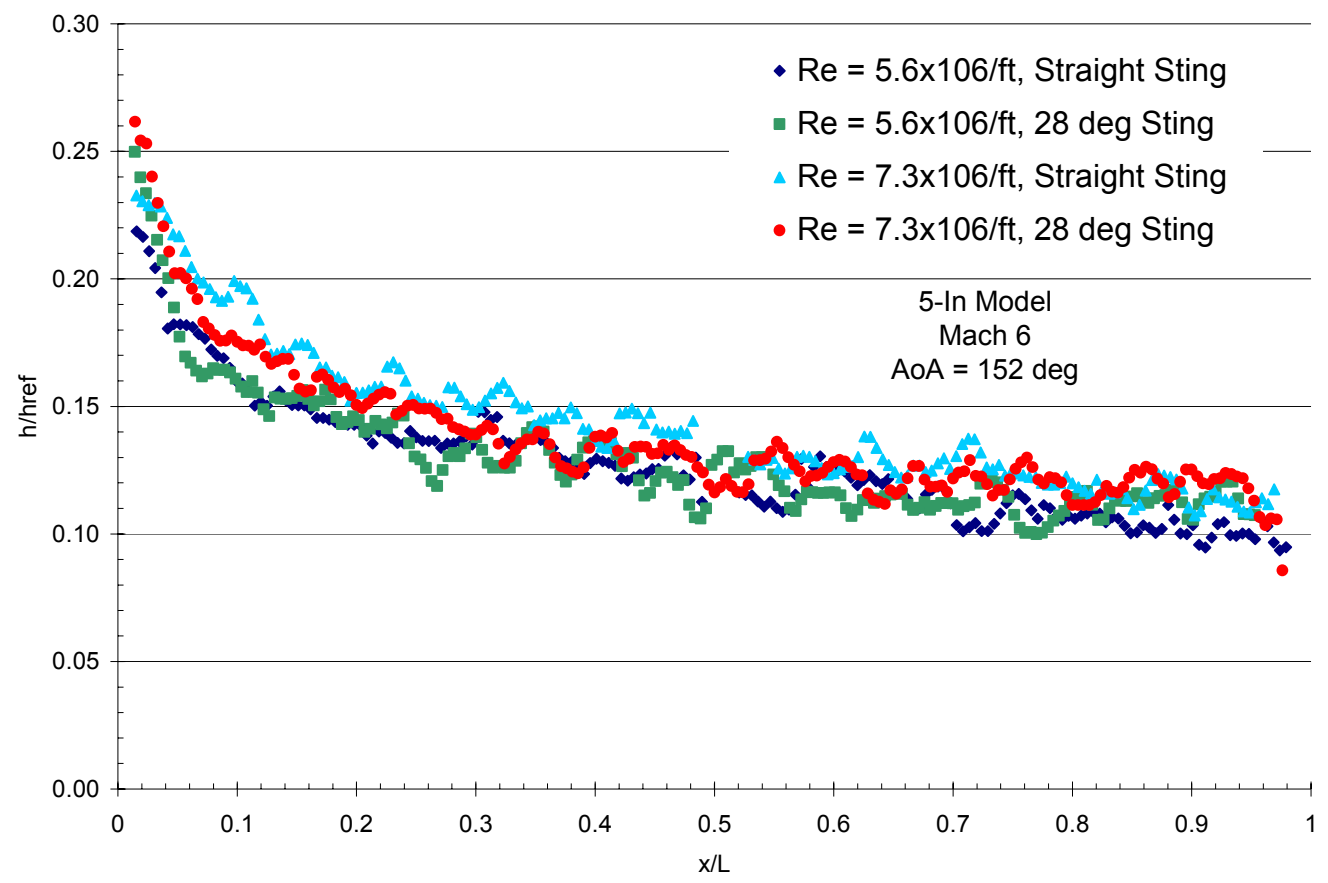

Figure 16: Windward Afterbody Testing at Mach 6; Straight, 28-deg Sting Models

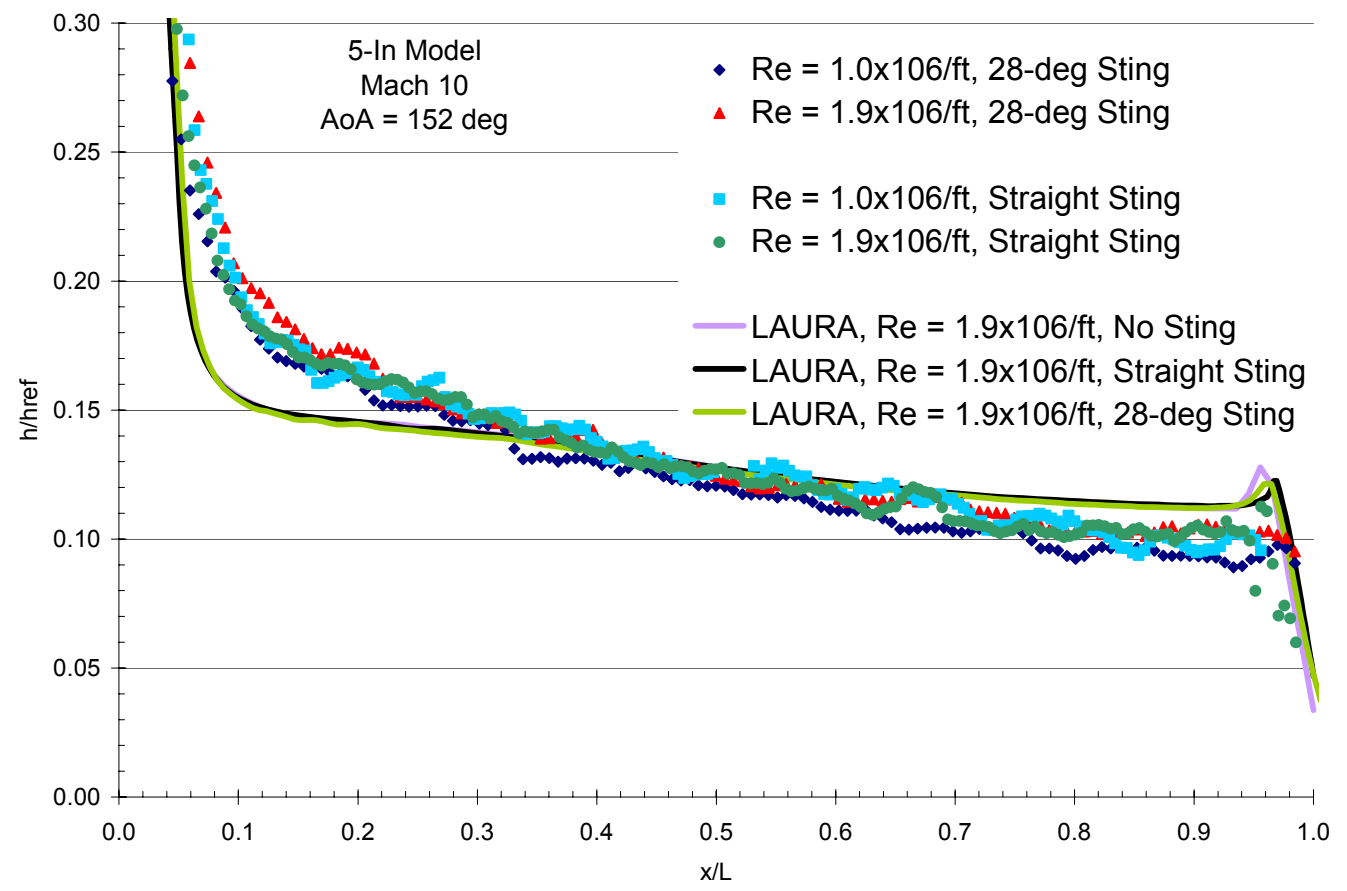

Figure 17: Windward Afterbody Testing at Mach 10; Straight, 28-deg Sting Models 


\section{Concluding Remarks}

Scaled models of the Crew Exploration Vehicle were tested in the Langley 20-Inch Mach 6 and 31-Inch Mach 10 Tunnels in order to obtain turbulent heating data and afterbody heating data. The primary objectives of the experiment were to determine the suitability of the two facilities for aeroheating data and to obtain turbulent forebody heating data for comparison to computational predictions. Additional objectives were to determine the scale model that could be tested in the facilities and to determine any effects of the placement of tunnel support hardware. The phosphor thermography system was used to gather global heating images in both facilities. Oil flow images were taken in the Mach 10 Tunnel. All but a limited number of blockage cases were run at the nominal flight angle of attach of $152 \mathrm{deg}$, and Reynolds number ranges of $2.1 \times 10^{6} / \mathrm{ft}-7.3 \times 10^{6} / \mathrm{ft}$ and $1.0 \times 10^{6} / \mathrm{ft}-1.9 \times 10^{6} / \mathrm{ft}$ in Mach 6 and Mach 10 tunnels, respectively. Boundary layer trips were necessary to ensure that the heating on the forebody in the Mach 6 facility was fully turbulent.

The experimental heating data collected with the phosphor thermography system were compared to computational predictions made with LAURA. On the forebody, heating rates at the two higher Reynolds number conditions match the predictions within 7\% for the Mach 6 tunnel. While both facilities were able to obtain afterbody heating data, the Mach 10 tunnel was more suited for the task as the noise levels for the data were lower. With the exception of the shoulder region near $\mathrm{x} / \mathrm{L}=0$, the experimental data compares well with the computational predictions. Both of the model scales that were tested in this series $(2.2 \%$ and $3.2 \%)$ showed no signs of tunnel flow blockage and are allowable for testing. There were no measurable effects of the support hardware configuration (straight sting or an offset sting) on the forebody or windside afterbody heating.

\section{Acknowledgments}

The author would like to thank the following people for their contributions to the project: Gary Wainwright, Mike Powers, Mark Griffith, Ed Covington, Pete Veneris and Kathy Kuykendoll for their assistance in model design, fabrication and preparation; Johnny Ellis, Paul Tucker, Anthony Robbins, Henry Fitzgerald, Grace Gleason, Harry Stotler, and Rhonda Mills for wind tunnel support; Kevin Hollingsworth, Sheila Wright and Teck-Sen Kwa for data acquisition assistance; Robert Nowak for test assistance; Thomas Horvath, Vincent Zoby, Randy Lillard and Ben Kirk for assistance in data interpretation and understanding; Maria Pulsonetti, Frank Greene and Steve Alter for LAURA computations. Without their help, these tests would not have been possible.

\section{References}

1 Buck, G. M., Powers, M. A., Griffith, M. S., Hopkins, J. W., Veneris, P. H., and Kuykendoll, K. A., "Fabrication of 0.0075-Scale Orbiter Phosphor Thermography Test Models for Shuttle RTF Aeroheating Studies," NASA TM-2006-214507, May 2006.

2 Micol J. R., "Langley aerothermodynamics facilities complex: enhancements and testing capabilities," AIAA Paper 98-0147, Jan 1998

3 Buck G. M., "Automated thermal mapping techniques using chromatic image analysis," NASA TM 101554, April 1989.

4 Merski N. R., "Reduction and analysis of phosphor thermography data with iheat software package," AIAA-980712, Jan 1998

5 Merski N. R., "Global aeroheating wind-tunnel measurements using improved two-color phosphor thermography model," Journal of Spacecraft and Rockets, Vol., 36, No., 2, 1998, pp. 160-170.

6 Fay, J. A., and Riddell, F. R., "Theory of Stagnation Point Heat Transfer in Dissociated Air," Journal of Aeronautical Sciences, Vol. 25, No. 2, 1958, pp. 73-85.

7 Berry, S. A., Hamilton, H. H., "Discrete Roughness Effects on Shuttle Orbiter at Mach 6," AIAA-2002-2744, June 2002.

8 Pulsonetti, M. V., Private Conversation, Presentation "CFD Support for the CEV Aeroheating Tests in LaRC's Mach 6 Air Facility," Jan 6, 2006.

9 Gnoffo, P. A. "An Upwind-Biased, Point-Implicit Relaxation Algorithm for Viscous Compressible Perfect Gas Flows," NASA TP 2953, Feb 1990.

10 Cheatwood, F. M., Gnoffo, P. A. "User's Manual for the Langley Aerothermodynamic Upwind Relaxation Algorithm (LAURA)," NASA TM 4674, April 1996 